\title{
Determinants of influenza vaccination uptake in pregnancy: a large single-Centre cohort study
}

Stéphanie Bartolo ${ }^{1,2^{*}}$ (D) Emilie Deliege ${ }^{3}$, Ophélie Mancel ${ }^{3}$, Philippe Dufour ${ }^{3}$, Sophie Vanderstichele ${ }^{3}$, Marielle Roumilhac ${ }^{3}$, Yamina Hammou ${ }^{3}$, Sophie Carpentier ${ }^{3}$, Rodrigue Dessein ${ }^{4}$, Damien Subtil ${ }^{1,3}$ and Karine Faure ${ }^{4,5}$

\begin{abstract}
Background: Although vaccination of pregnant women against influenza is recommended, the vaccination rate remains low. We conducted a study to identify determinants of influenza vaccination uptake in pregnancy in order to identify strategies to improve seasonal influenza vaccination rates.

Methods: Prospective observational hospital-based study in the French hospital performing the highest number of deliveries, located in the city of Lille, among all women who had given birth during the 2014-2015 influenza season. Data were collected through a self-completed questionnaire and from medical files. The vaccination uptake was self-reported. Determinants of vaccination uptake were identified using logistic regression analysis.

Results: Of the 2045 women included in the study, 35.5\% reported that they had been vaccinated against influenza during their pregnancy. The principal factors significantly associated with greater vaccination uptake were previous influenza vaccination ( $50.9 \%$ vs $20.2 \%$, OR $4.1,95 \%$ Cl $3.1-5.5)$, nulliparity (41.0\% vs $31.3 \%$, OR 2.5, 95\% Cl 1.7-3.7), history of preterm delivery < 34 weeks ( $43.4 \%$ vs $30.3 \%$, OR $2.3,95 \%$ Cl 1.1-4.9), the mother's perception that the frequency of vaccine complications for babies is very low (54.6\% vs $20.6 \%$, OR $1.1,95 \% \mathrm{Cl} 0.5-2.2)$, the mother's good knowledge of influenza and its vaccine (61.7\% vs $24.4 \%$, OR 3.1, 95\% Cl 2.2-4.4), hospital-based prenatal care in their first trimester of pregnancy $(55.0 \%$ vs $30.2 \%$, OR $2.1,95 \% \mathrm{Cl} 1.2-3.7)$, vaccination recommendations during pregnancy by a healthcare worker (47.0\% vs $2.7 \%$, OR 18.8, 95\% Cl 10.0-35.8), receipt of a vaccine reimbursement form ( $52.4 \%$ vs $18.6 \%$, OR $2.0,95 \% \mathrm{Cl} 1.5-2.7)$, and information from at least one healthcare worker about the vaccine ( $43.8 \%$ vs $19.1 \%$, OR $1.8,95 \% \mathrm{Cl} 1.3-2.6)$.

Conclusions: Our findings suggest that in order to increase flu vaccination compliance among pregnant women, future public health programmes must ensure cost-free access to vaccination, and incorporate education about the risks of influenza and the efficacy/safety of vaccination and clear recommendations from healthcare professionals into routine antenatal care.
\end{abstract}

Keywords: Influenza vaccine, Pregnancy, Health knowledge, Behaviours

\footnotetext{
* Correspondence: stephanie.bartolo@gmail.com

${ }^{1}$ University Lille, EA 2694 : épidémiologie et qualité des soins, pôle recherche aile Est 2ème étage, 59045 cedex, 1 Place de Verdun, 59000 Lille, France ${ }^{2}$ Douai hospital, route de Cambrai, -, 10740 - 59507 Douai Cedex, BP, France Full list of author information is available at the end of the article
}

(c) The Author(s). 2019 Open Access This article is distributed under the terms of the Creative Commons Attribution 4.0 International License (http://creativecommons.org/licenses/by/4.0/), which permits unrestricted use, distribution, and reproduction in any medium, provided you give appropriate credit to the original author(s) and the source, provide a link to the Creative Commons license, and indicate if changes were made. The Creative Commons Public Domain Dedication waiver (http://creativecommons.org/publicdomain/zero/1.0/) applies to the data made available in this article, unless otherwise stated. 


\section{Introduction}

Seasonal influenza is a common and contagious illness with an annual attack rate estimated at $5-10 \%$ in adults [1], pregnant women being at increased risks of morbidity and death [1], even those with no comorbidities [2].

Seasonal influenza vaccination during pregnancy reduces the risk of an influenza diagnosis by $50 \%$ [3]. It also confers effective protection up to the age of 6 months for newborns whose mother was vaccinated during pregnancy [4] with a reduction of $63 \%$ in influenza cases and of $29 \%$ in episodes of febrile respiratory illness [5]. A review of 15 years of surveillance data covering 750 million doses of the vaccine in the United States revealed no data that raised concerns about its safety in general population [6], neither for the foetus nor the mother, as showed by other studies [7-10]. As a result, the World Health Organization (WHO) [11], the American College of Obstetricians and Gynecologists and the Centers for Disease Control and Prevention (CDC) [12], recommend seasonal influenza vaccination for pregnant women, regardless of gestational age.

Several previous studies have identified factors affecting pregnant women's decisions about whether to get a seasonal influenza vaccination [13-17]. Despite this, the vaccination coverage in pregnant women remains very low: 7\% in France in 2016 [18], 45\% in England in 2017 [19], and 37\% in the US in 2017 [20] and lower than the Healthy People 2020 target of 80\% [21]. Therefore, to explore why the vaccination coverage remains very low, we conducted one of the largest cohort studies on this topic to date to evaluate women motivations to be vaccinated or not. We also investigated a large number of possible determinants, in order to find strategies to improve seasonal influenza vaccination rate.

\section{Material and methods}

\section{Study design and sampling method}

We conducted a prospective single centre observational study during the 2014-2015 influenza season in a levelIII University maternity unit in Lille, France, with an approximate birth rate of 5000 births/year. In France, women must obtain a prescription and a reimbursement form from their general practitioner or antenatal care provider, purchase the vaccine from a drugstore and the vaccine may then be administered during another appointment with the healthcare worker conducting the antenatal care or by a nurse at home. The vaccine is cost-free if the woman provides the drugstore with a reimbursement form. Eligible women for the study were all the women giving birth in our maternity unit and having received prenatal care during the 2014-2015 vaccination campaign between November 17, 2014, and June 5,2015 . The study excluded those younger than 18 years, or who did not speak French, or had a contraindication to the influenza vaccination, or refused to participate. For all participants written consent was obtained.

\section{Variables considered in our study}

The outcome of interest was seasonal influenza vaccination uptake, reported by the pregnant women as part of a self-completed questionnaire. Data were collected from medical forms and from a self-completed paper questionnaire (see Additional file 1 and Additional file 2)offered by the clinical staff to all eligible women during their postpartum hospitalisation. Variables considered as possible determinants of vaccine uptake were

1. maternal sociodemographic characteristics: age, educational level and living or not with her partner;

2. maternal medical characteristics before pregnancy: pre-existing comorbidities for which influenza vaccination is indicated according to French guidelines (grouped into major categories: respiratory, cardiac, neurological, kidney-related, haematological and immune-related, diabetes, chronic liver disease, and obesity with Body Mass Index $(\mathrm{BMI}) \geq 40 \mathrm{~kg} / \mathrm{m}^{2}$ [22]), being vaccinated against influenza before this pregnancy, number of previous deliveries, history of preterm delivery before 34 weeks;

3. characteristics of the current pregnancy: smoking status, obstetrical complications defined as gestational diabetes, gestational hypertension, preeclampsia, HELLP syndrome, infections and foetal growth restriction;

4. antenatal care: the starting time of prenatal care at the hospital, the healthcare worker providing the prenatal care being a gynaecologist-obstetrician, general practitioner, hospital midwife, private midwife, profession of the healthcare worker recommending the vaccination, the provision of a reimbursement form for the vaccine;

5. maternal knowledge about influenza and its vaccine: frequency of influenza, knowledge of serious complications of influenza for mothers and their infants, the frequency of vaccine complications for mothers and their infants, knowledge about the recommendation of the vaccine in pregnancy.

Data about maternal sociodemographic characteristics, maternal medical characteristics before pregnancy, and characteristics of this pregnancy were extracted from the medical forms. Prenatal care and maternal knowledge about influenza and its vaccine were extracted from the selfcompleted questionnaire. The questionnaire was adapted from the questionnaire used by Yudin et al. to assess women's knowledge of influenza and its vaccination [23]. 
We also created a "knowledge score" about this disease and its vaccine before the study with a multidisciplinary group of experts including obstetricians, infectious disease specialists, general practitioners, and statisticians from the potential responses to the self-completed questionnaire (see Additional file 3). The score ranged from 0 to 9 points and a woman was considered to have good knowledge when her score was higher than the last quartile of the score distribution, that is, a knowledge score greater than 5.4/9 in our study.

\section{Statistical analyses}

To identify determinants associated with vaccination uptake, we conducted bivariate and multivariate logistic regression analysis. Dependent variables included in the regression model were those previously described as determinants of vaccine uptake in scientific literature or associated with vaccination uptake in bivariate analysis with a $p$-value less than 0.20 . We have calculated variance inflation factor to check for multicollinearity and all the variables have a VIF $<2.0$. In order to evaluate if the profession of the healthcare worker recommending the vaccination was a relevant factor, we conducted an analysis only on women to whom vaccination had been recommended during pregnancy. Percentages were compared using the chi-2 test or Fisher's exact test, depending on the number of individuals. We calculated adjusted odds ratios (aORs) with their 95\% confidence interval $(95 \% \mathrm{CI})$. The difference was considered significant if $p<0.05$. The analyses were performed with STATA software version 13.0.0 (Copyright 1985-2013 StataCorp LP, StataCorp, College Station, TX, USA).

Our study adheres to the STROBE guidelines. The CEROG (committee for ethics in research in gynaecology and obstetrics, $n^{\circ}$ CEROG OBS 2014-11-01) approved of this study.

\section{Results}

Of the 2862 women who gave birth during the inclusion period, 370 did not receive the questionnaire (12.9\%), 138 were excluded from the study (5.5\%), 216 women received the questionnaire but did not return it (9.2\%), and 24 women did not answer the question about their

2862 women gave birth

between November 17, 2014, and June 5, 2015
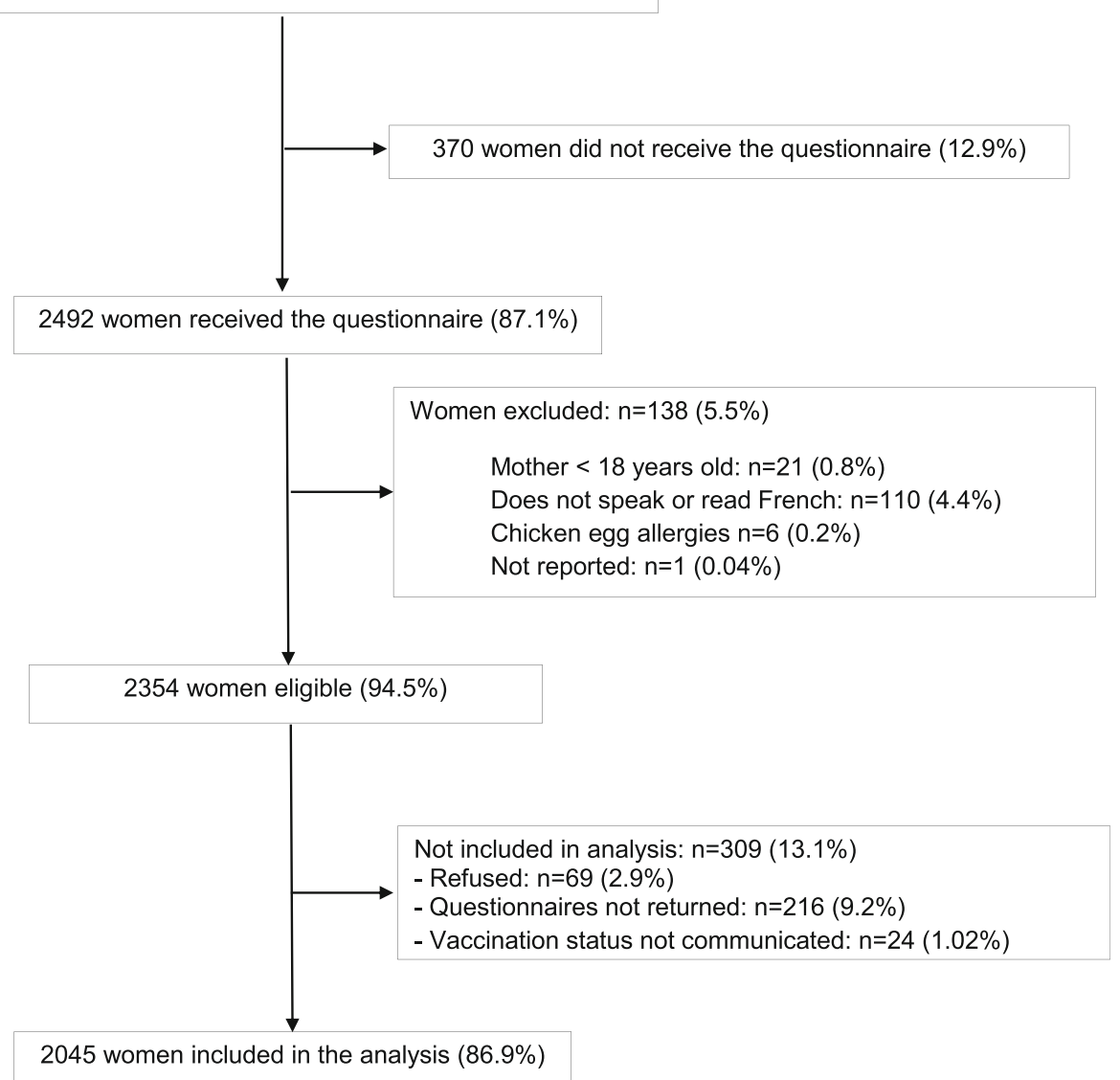

Fig. 1 Strengthening the Reporting of Observational Studies in Epidemiology (STROBE) flow diagram of the participants in this study 
Table 1 Factors associated with uptake of influenza vaccination during pregnancy according to mothers' characteristics ( $n=$ 2045)

\begin{tabular}{llll}
\hline & \multicolumn{3}{l}{ Vaccinated } \\
\cline { 2 - 4 } & $\mathrm{n} / \mathrm{N}^{a}$ & $\%$ & $p^{*}$ \\
\hline Total & $725 / 2045$ & 35.5 &
\end{tabular}

Age

$\begin{array}{llll}<25 \text { years } & 97 / 306 & 31.7 & 0.49 \\ \geq 25 \text { and }<30 \text { years } & 230 / 645 & 35.7 & \\ \geq 30 \text { and }<35 \text { years } & 246 / 685 & 35.9 \\ \geq 35 \text { years } & 151 / 408 & 37.0\end{array}$

Educational level

$\begin{array}{lll}\text { Primary } & 28 / 69 & 40.6 \\ \text { Secondary or technical } & 132 / 386 & 34.2 \\ \text { Higher study } & 564 / 1588 & 35.5 \\ \text { Lives with partner } & & \\ \text { Yes } & 643 / 1803 & 35.7 \\ \text { No } & 81 / 240 & 33.7\end{array}$

Smoked during pregnancy

Yes

$144 / 437 \quad 33.0$

No

$578 / 1602 \quad 36.1$

At least one comorbidity ${ }^{\mathrm{b}}$

$191 / 478 \quad 40.0$

Respiratory

$48 / 142 \quad 33.8$

Cardiac

$28 / 74 \quad 37.8$

Neurological

$36 / 93$

38.7

Nephrological

$9 / 18 \quad 50.0$

Haematologic-immune

$31 / 54 \quad 57.4$

Diabetes

$16 / 30 \quad 53.3$

Chronic liver disease

$10 / 21 \quad 47.6$

$\mathrm{BMI} \geq 40 \mathrm{~kg} / \mathrm{m}^{2}$

$13 / 24$

29.5

Previous influenza vaccination

Yes, outside pregnancy

Yes, during a previous pregnancy

No

$279 / 548 \quad 50.9$

$185 / 201 \quad 92.0$

$249 / 1235 \quad 20.2$

Number of previous deliveries

$\begin{array}{llll}0 & 358 / 874 & 41.0 & <0.001 \\ 1 & 225 / 704 & 32.0 & \\ \geq 2 & 141 / 465 & 30.3 & \end{array}$

History of preterm delivery $<34$ weeks

$\begin{array}{lll}\text { Yes } & 33 / 76 & 43.4 \\ \text { No } & 691 / 1967 & 35.1\end{array}$

Obstetric complications ${ }^{c}$

Yes

$288 / 812 \quad 35.5$

No

$435 / 1228 \quad 35.4$

Perceived frequency of influenza in the general population

very low to low

$49 / 180 \quad 27.2$

Intermediate

$217 / 631 \quad 34.4$

Table 1 Factors associated with uptake of influenza vaccination during pregnancy according to mothers' characteristics ( $n=$ 2045) (Continued)

\begin{tabular}{llll}
\hline & \multicolumn{3}{l}{ Vaccinated } \\
\cline { 2 - 4 } & $\mathrm{n} / \mathrm{N}^{\mathrm{a}}$ & $\%$ & $p^{¥}$ \\
\hline High & $452 / 1202$ & 37.6 &
\end{tabular}

Perceived frequency of vaccine complications in pregnant women

$\begin{array}{llll}\text { Very low } & 352 / 673 & 52.3<0.001 \\ \text { Low } & 154 / 509 & 30.3 & \\ \text { Intermediate } & 139 / 597 & 23.3 \\ \text { High } & 52 / 141 & 36.9\end{array}$

Perceived frequency of vaccine complications in babies

0.59

very low

Low

Intermediate

High

$375 / 687 \quad 54.6$

$<0.001$

0.56

Good knowledge of influenza ${ }^{ \pm}$

Yes

$122 / 414 \quad 29.5$

$128 / 621 \quad 20.6$

$64 / 181 \quad 35.4$

No

$374 / 606$

61.7

$<0.001$

0.02

${ }^{a}$ Number of women vaccinated among the total number of women in the subclass

${ }^{b}$ Presence of at least one comorbidity that is an indication for influenza vaccination even outside of pregnancy according to the 2012 HAS guidelines [32]

'Gestational diabetes, hypertension, pre-eclampsia, HELLP syndrome,

infections, other (anaemia, foetal growth restriction, etc.)

$¥ p$ value was calculated by Chi 2 test

\pm good knowledge of influenza was defined by a knowledge score $>5.4 / 9$

influenza vaccination. Therefore, 2045 women (86.9\%) were included in the analysis (Fig. 1).

One third of the women questioned (35.5\%) reported they had been vaccinated against seasonal influenza during their pregnancy. Table 1 presents the maternal factors associated with this vaccination. Women were vaccinated more often if they had at least one comorbidity (40.0\%), if they had previously been vaccinated against influenza (50.9\%), especially during a previous pregnancy $(92.0 \%)$, and if they were nulliparous (41.0\%). Higher vaccination rates were also observed for women who perceived influenza as a common disease (37.6\%), or its vaccination as having a very low rate of complications for mothers $(52.3 \%)$ or babies $(54.6 \%)$, and when they had good knowledge about influenza (61.7\%). Note that educational level and severe obesity $\left(\mathrm{BMI}>40 \mathrm{~kg} / \mathrm{m}^{2}\right)$ were not associated with vaccination.

The prenatal care factors associated with vaccination (Table 2) were hospital-based prenatal care in their first trimester of pregnancy $(55.0 \%)$, having received a vaccination recommendation (47.0\%), especially by a general practitioner $(57.3 \%)$ or a midwife in private practice (54.3\%), receipt of a vaccine reimbursement form (52.4\%), or information from a healthcare worker (43.8\%). 
Table 2 Factors associated with uptake of influenza vaccination during pregnancy according to prenatal care $(n=2045)$

\begin{tabular}{|c|c|c|c|}
\hline & \multicolumn{3}{|l|}{ Vaccinated } \\
\hline & $n / N^{a}$ & $\%$ & $p^{*}$ \\
\hline Total & $725 / 2045$ & 35.5 & \\
\hline \multicolumn{4}{|l|}{ Time at which prenatal care started } \\
\hline First trimester & $72 / 131$ & 55.0 & \multirow[t]{3}{*}{$<0.001$} \\
\hline Second trimester & $410 / 1106$ & 37.1 & \\
\hline Third trimester & $241 / 798$ & 30.2 & \\
\hline \multicolumn{4}{|l|}{ Healthcare worker providing the prenatal care } \\
\hline Assistant Chief Resident & $50 / 129$ & 38.8 & \multirow[t]{4}{*}{0.80} \\
\hline Hospital staff physician & 274,734 & 37.3 & \\
\hline Hospital staff midwife & $322 / 894$ & 36.0 & \\
\hline Intern & $64 / 187$ & 34.2 & \\
\hline \multicolumn{4}{|l|}{ Healthcare worker recommending vaccination } \\
\hline Gynaecologist-Obstetrician & $237 / 467$ & 50.7 & \multirow[t]{6}{*}{$<0.001$} \\
\hline General practitioner & $82 / 143$ & 57.3 & \\
\hline Hospital staff midwife & $229 / 571$ & 40.1 & \\
\hline Midwife (in private practice) & $25 / 46$ & 54.3 & \\
\hline Several different professionals & $76 / 158$ & 48.1 & \\
\hline Occupational doctor, national health insurance & $56 / 107$ & 52.3 & \\
\hline \multicolumn{4}{|l|}{ Types of information received } \\
\hline Recommendation for vaccination with a form for reimbursement & $524 / 987$ & 53.1 & \multirow[t]{4}{*}{$<0.001$} \\
\hline Recommendation for vaccination without a form for reimbursement & $176 / 501$ & 35.1 & \\
\hline No recommendation for vaccination but reimbursement form provided & $3 / 19$ & 15.8 & \\
\hline Neither proposal for vaccination nor reimbursement form & $11 / 507$ & 2.2 & \\
\hline \multicolumn{4}{|l|}{ Vaccination recommendation } \\
\hline Yes & $711 / 1514$ & 47.0 & \multirow[t]{2}{*}{$<0.001$} \\
\hline No & $14 / 528$ & 2.7 & \\
\hline \multicolumn{4}{|l|}{ Receipt of a vaccine reimbursement form } \\
\hline Yes & $527 / 1006$ & 52.4 & \multirow[t]{2}{*}{$<0.001$} \\
\hline No & 187/1008 & 18.6 & \\
\hline \multicolumn{4}{|l|}{ Sources of information about influenza vaccination (multiple responses possible) } \\
\hline At least one healthcare worker & $604 / 1378$ & 43.8 & \multirow[t]{2}{*}{$<0.001$} \\
\hline Not a healthcare worker ${ }^{\mathrm{b}}$ & 117/611 & 19.1 & \\
\hline
\end{tabular}

${ }^{a}$ Number of women vaccinated among the total number of women in the subclass

${ }^{\mathrm{b}}$ All answers possible except healthcare workers: the media, discussion groups, family and friends, health authorities, and others $¥ p$ value was calculated by Chi 2 test

Women motivations to be vaccinated or not are summarised in Table 3. The major motivation to be vaccinated was that the vaccine protects the baby $(83 \%)$ and at the second place that the vaccine protects her (73\%). A third of the vaccinated women claimed as motivation that they had received sufficient information about the benefits of the vaccine. However, there was a variety of reasons to not be vaccinated: some did not have enough information about the benefit and risk of the vaccine (32\%), some were rather "against" vaccines in general $(26 \%)$ and others were scared for the baby's health (24\%).
On logistic regression analysis (Table 4), statistically significant determinants of vaccination were a previous influenza vaccination $(50.9 \%$ vs $20.2 \%$, OR $4.1,95 \%$ CI $3.3-$ $5.5)$, nulliparity (41.0\% vs $30.3 \%$, OR 2.5 , 95\% CI $1.7-3.7$ ), history of preterm delivery < 34 weeks $(43.4 \%$ vs $35.1 \%$, OR $2.3,95 \%$ CI 1.1-4.9), perception that the frequency of vaccine complications for babies is very low $(54.6 \%$ vs $35.4 \%$,OR 1.1, 95\% CI 0.5-2.2), the mothers' good knowledge of influenza and the vaccine $(61.7 \%$ vs $24.4 \%$,OR 3.1 , 95\% CI 2.2-4.4), hospital-based prenatal care in their first trimester of pregnancy $(55 \%$ vs $30.2 \%$, OR $2.1,95 \%$ CI 
Table $\mathbf{3}$ Women motivations to be vaccinated or not against influenza

\begin{tabular}{lll}
\hline & $n$ & \\
\hline Motivations to be vaccinated $(N=325)$ & 529 & \\
The vaccine protects me & 599 & 73.0 \\
The vaccine protects my baby & 217 & 82.6 \\
I have received sufficient information on the benefits of the vaccine & 172 & 30.0 \\
I am more "in favour" of vaccines in general & 64 & 23.7 \\
The vaccine is fully reimbursed & 23 \\
Other & & 3.8 \\
Motivations not to be vaccinated ( $N=1320)$ & 55 \\
I did not know there was a vaccine & 317 \\
I was scared for my baby's health & 166 \\
I was scared for my health & 422 \\
I did not have enough information about the benefits and risks & 3.2 \\
I am rather "against" vaccines in general & 350 \\
Other & 387 \\
\hline
\end{tabular}

$1.2-3.7)$, vaccination recommendations ( $47.0 \%$ vs $2.7 \%$, OR 18.8, 95\% CI 10.0-35.8) and when this recommendation was done by a general practitioner $(57.3 \%$ vs $50.7 \%$ for Gynaecologist-Obstetrician, OR 1.6 CI 1.0-2.8), receipt of a vaccine reimbursement form $(52.4 \%$ vs $18.6 \%$, OR 2.0, 95\% CI 1.5-2.7), and having received information about the vaccine from at least one healthcare worker (43.8\% vs $19.1 \%$, OR 1.8 , 95\% CI 1.3-2.6).

\section{Discussion}

Our study examined the potential determinants of the influenza vaccination uptake amongst pregnant women in a single centre in France.

Overall, our findings highlight the importance of the healthcare worker in vaccination uptake. Indeed, vaccination recommendation by a healthcare provider strongly influence vaccination uptake (aOR 19). In addition to making a recommendation, the influence of healthcare worker was also vital in educating women about the influenza and the vaccine and providing reimbursement form.

Indeed, among factors that may be modified to improve the vaccination rate, we found, similar to other authors, that several are related to knowledge and perception of influenza, its vaccine and its potential complications $[13-15,17,23,24]$. Moreover, our study found that protecting the baby against influenza was the leading motivation for vaccination among those pregnant women who were vaccinated $(83 \%)$. In a systematic review of the literature on the subject, $41 \%$ of the articles studied found that vaccine safety was a major concern among pregnant women, for all vaccines combined [25]. Furthermore, our study demonstrates the role of healthcare professionals as an essential source of information for the pregnant women who are vaccinated. Inversely, sources of information such as television, radio, the print media, the internet, family and friends are associated with lower vaccination rates in our study and in the literature [13, 25, 26]. Conversely, good knowledge of influenza and its vaccine was closely associated with vaccination among the women questioned in our study. This should provide incentives to implement measures to improve the quality of information provided to women by healthcare worker $[15,27]$.

Concerning the major impact of the recommendation and provision of the reimbursement form by healthcare worker, our results are corroborated by the data from the literature: an analysis by the CDC for the 2016-2017 influenza season in the US showed that the vaccination rate among pregnant women reached $70.5 \%$ among women whose providers recommended and offered the vaccination, $43.7 \%$ when the vaccine was recommended but not offered, and $14.8 \%$ when it was neither recommended nor offered [20] (53\%, 35 and 2\% in our study).

In France, women must obtain a prescription from their GP or antenatal care provider, purchase the vaccine, and subsequently attend again to receive the vaccine. This process may be a significant barrier to the vaccine uptake. Several experiments are in process in France to study if getting the vaccine without prescription and injecting it at the same time in the drugstore can improve the vaccination coverage.

We found several other factors associated with increased vaccination rate but not easily modifiable by a public health program such as nulliparity $[15,17]$, history of preterm delivery or hospital based prenatal care in their first trimester of pregnancy $[15,28]$.

So, our study highlights the importance of incorporating education about the risk of flu and the safety/efficacy of vaccination into routine antenatal care. The pregnant women need to know that the vaccine protects them 
Table 4 Logistical regression analysis of the factors associated with influenza vaccination uptake during pregnancy in this study $(n=1751)$

\begin{tabular}{|c|c|c|c|c|}
\hline & OR & $\mathrm{aOR}^{\mathrm{a}}$ & $95 \% \mathrm{Cl} \%{ }^{\mathrm{b}}$ & $p^{*}$ \\
\hline \multicolumn{5}{|l|}{ Previous influenza vaccination } \\
\hline No. & 1 & 1 & & \multirow[t]{3}{*}{$<0.001$} \\
\hline Yes, not during pregnancy & 4.1 & 4.1 & $3.1-5.5$ & \\
\hline Yes, in a previous pregnancy & 45.8 & 43.9 & $22.8-84.4$ & \\
\hline \multicolumn{5}{|l|}{ Number of previous deliveries } \\
\hline$\geq 2$ & 1 & 1 & & \multirow[t]{3}{*}{$<0.001$} \\
\hline 1 & 1.1 & 1.6 & $1.1-2.4$ & \\
\hline 0 & 1.6 & 2.5 & $1.7-3.7$ & \\
\hline \multicolumn{5}{|l|}{ History of preterm delivery $<34$ weeks } \\
\hline No. & 1 & 1 & & \multirow[t]{2}{*}{0.02} \\
\hline Yes & 1.4 & 2.3 & $1.1-4.9$ & \\
\hline \multicolumn{5}{|c|}{ Perceived frequency of vaccine complications in babies } \\
\hline High & 1 & 1 & & \multirow[t]{4}{*}{0.005} \\
\hline Intermediate & 0.3 & 0.9 & $0.5-1.5$ & \\
\hline Low & 0.2 & 0.5 & $0.3-0.9$ & \\
\hline Very low & 0.4 & 1.1 & $0.5-2.2$ & \\
\hline \multicolumn{5}{|l|}{ Good knowledge of influenza } \\
\hline No. & 1 & 1 & & \multirow[t]{2}{*}{$<0.001$} \\
\hline Yes & 5.0 & 3.1 & $2.2-4.4$ & \\
\hline \multicolumn{5}{|l|}{ Hospital-based prenatal care beginning } \\
\hline Third trimester & 1 & 1 & & \multirow[t]{3}{*}{0.02} \\
\hline Second trimester & 1.4 & 1.2 & $0.9-1.6$ & \\
\hline First trimester & 2.8 & 2.1 & $1.2-3.7$ & \\
\hline \multicolumn{5}{|l|}{ Vaccination recommendation } \\
\hline No. & 1 & 1 & & \multirow[t]{2}{*}{$<0.001$} \\
\hline Yes & 32.5 & 18.8 & $10.0-35.8$ & \\
\hline \multicolumn{5}{|l|}{ Receipt of a vaccine reimbursement form } \\
\hline No. & 1 & 1 & & \multirow[t]{2}{*}{$<0.001$} \\
\hline Yes & 4.8 & 2.0 & $1.5-2.7$ & \\
\hline \multicolumn{5}{|c|}{ Profession of the healthcare worker offering the vaccination ${ }^{£}$} \\
\hline Gynaecologist-Obstetrician & 1 & 1 & & \multirow[t]{6}{*}{0.05} \\
\hline General practitioner & 1.3 & 1.6 & $1.0-2.8$ & \\
\hline Hospital staff midwife & 0.6 & 0.9 & $0.6-1.3$ & \\
\hline Midwife (in private practice) & 1.1 & 2.2 & $0.9-5.1$ & \\
\hline Several different professionals & 0.9 & 1.2 & $0.7-1.9$ & \\
\hline Occupational doctor, national health insurance & 1.1 & 1.7 & $1.0-2.9$ & \\
\hline \multicolumn{5}{|c|}{ Sources of information about influenza vaccination (multiple responses possible) } \\
\hline No healthcare worker ${ }^{c}$ & 1 & 1 & & \multirow[t]{2}{*}{$<0.001$} \\
\hline At least one healthcare worker & 3.3 & 1.8 & $1.3-2.6$ & \\
\hline
\end{tabular}

${ }^{a}$ Adjusted odds ratio: determined by multivariate logistic regression of influenza vaccination for the variables with a $p$-value $<0.20$. The variables not significantly associated with vaccination $(p>0.05)$ are not presented: the presence of at least one comorbidity ${ }^{\mathrm{b}}$, perceived frequency of influenza, and perceived frequency of vaccine complications in mothers

${ }^{\mathrm{b}} 95 \%$ confidence interval

${ }^{c}$ All answers possible except healthcare workers: the media, discussion groups, family and friends, health authorities, and others

$¥ p$ value was calculated by multivariate logistic regression analyses

$£$ Only women who had received a vaccination recommendation were analysed $(n=1300)$ 
and their newborns from influenza infection and that there are very few vaccine complications for them and their babies. Our study suggests that this simple message delivered by a healthcare worker can improve the vaccination uptake.

\section{Implications for future practice and research}

Our study suggests that in order to increase influenza vaccine compliance among pregnant women, two principal actions should guide prenatal care policies: information about influenza and its vaccine by healthcare workers and cost-free access to the vaccine. As the role of professionals appears central, it would be useful to conduct a study in order to assess their knowledge and opinions about this vaccination and to help them to improve their practice by incorporating education about influenza vaccination during their routine antenatal care.

\section{Strengths and limitations}

On the one hand, the prospective nature of our study, the number of women included, the high participation rate $(87 \%)$, and the use of a self-completed questionnaire enabled us to limit the potential for bias as much as possible. On the other hand, its single-centre nature could have induced recruitment bias, and the responses cannot be taken as representative of all pregnant women. Another limitation might be that our participants were all recruited from a university hospital, and that our sample may therefore be missing subsets of the population that tend to be more anti-vaccination or receive less education, so future studies might benefit from recruiting over a wider geographical area and from different types of sites. Finally, vaccination status was reported by the women and there is therefore potentially susceptible to reporting bias, which has been partially corrected by checking the women's medical records.

\section{Conclusions}

Although the World Health Organization has recommended influenza vaccination for all pregnant women since 2012, only one third of the mothers in our study were vaccinated. Our study highlights that in order to increase influenza vaccination compliance among pregnant women, two principal actions should guide prenatal care policies: information about influenza and its vaccine be routinely given by healthcare workers and cost-free access to the vaccine.

\section{Supplementary information}

Supplementary information accompanies this paper at https://doi.org/10. 1186/s12884-019-2628-5.

Additional file 1. Questionnaire in French

Additional file 2. Questionnaire in English
Additional file 3. Knowledge score, a.File explaining how the knowledge score was constructed

\section{Abbreviations}

95\% Cl: 95\% confidence interval; aORs: Adjusted odds ratios; BMI: Body Mass Index; CDC: Centers for Disease Control and Prevention; CEROG: Committee for ethics in research in gynaecology and obstetrics; HELLP

syndrome: Haemolysis, Elevated Liver enzymes and Low Platelet count syndrome; OR: Odds ratio; US: The United States; WHO: World Health

Organization

\section{Acknowledgements}

Not applicable.

\section{Authors' contributions}

SB was a major contributor in writing the manuscript and statistical analyses. $\mathrm{ED}$ and $\mathrm{OM}$ were contributors in writing the manuscript and in the acquisition of data. PD, SV, MR, YH were contributors in the acquisition of data and were involved in revising the manuscript critically. SC made substantial contributions to conception and design of the study. RD was involved in revising the manuscript critically. DS and KF have substantial contributions to conception and design of the study and were involved in revising the manuscript critically. All authors read and approved the final manuscript.

Funding

no funding.

\section{Availability of data and materials}

All datasets analysed during this study are presented in an additional supporting file.

\section{Ethics approval and consent to participate}

The CEROG (committee for ethics in research in gynaecology and obstetrics, $n^{\circ}$ CEROG OBS 2014-11-01) approved of the study and our research had been performed in accordance with the declaration of Helsinki. It belongs to the French national college of gynaecology and obstetrics. For all participants a written consent was obtained.

\section{Consent for publication}

Not applicable.

\section{Competing interests}

The authors declare that they have no competing interests.

\section{Author details}

'University Lille, EA 2694 : épidémiologie et qualité des soins, pôle recherche aile Est 2ème étage, 59045 cedex, 1 Place de Verdun, 59000 Lille, France.

${ }^{2}$ Douai hospital, route de Cambrai, -, 10740 - 59507 Douai Cedex, BP, France. 3University Lille, CHU Lille, Pôle Femme Mère Nouveau-né, Avenue Eugène Avinée, 59000 Lille, France. ${ }^{4}$ University Lille, EA7366, Recherche

Translationelle Relation Hôte-Pathogènes, Faculté de Médecine Pôle Recherche 5 ème étage Ouest, 1 Place de Verdun, 59045 Lille, France. ${ }^{5}$ University Lille, CHU Lille, Service de Maladies Infectieuses, rue Michel Polonowski, 59000 Lille, France.

Received: 20 June 2018 Accepted: 22 November 2019 Published online: 19 December 2019

\section{References}

1. Vaccines against influenza WHO position paper - November 2012. Relevé Épidémiologique Hebd Sect Hygiène Secrétariat Société Nations Wkly Epidemiol Rec Health Sect Secr Leag Nations. 2012:87:461-76.

2. Anselem $O$, Floret $D$, Tsatsaris V, Goffinet F, Launay O. [Influenza infection and pregnancy]. Presse Médicale Paris Fr 1983. 2013:42:1453-60.

3. Madhi SA, Cutland CL, Kuwanda L, Weinberg A, Hugo A, Jones S, et al. Influenza vaccination of pregnant women and protection of their infants. $N$ Engl J Med. 2014;371:918-31. 
4. Steinhoff MC, Omer SB, Roy E, Arifeen SE, Raqib R, Altaye M, et al. Influenza immunization in pregnancy--antibody responses in mothers and infants. N Engl J Med. 2010;362:1644-6.

5. Zaman K, Roy E, Arifeen SE, Rahman M, Ragib R, Wilson E, et al. Effectiveness of maternal influenza immunization in mothers and infants. N Engl J Med. 2008;359:1555-64.

6. Vellozzi C, Burwen DR, Dobardzic A, Ball R, Walton K, Haber P. Safety of trivalent inactivated influenza vaccines in adults: background for pandemic influenza vaccine safety monitoring. Vaccine. 2009;27:2114-20.

7. Louik C, Kerr S, Van Bennekom CM, Chambers C, Jones KL, Schatz M, et al. Safety of the 2011-12, 2012-13, and 2013-14 seasonal influenza vaccines in pregnancy: preterm delivery and specific malformations, a study from the case-control arm of VAMPSS. Vaccine. 2016:34:4450-9.

8. Chambers CD, Johnson DL, Xu R, Luo YJ, Louik C, Mitchell AA, et al. Safety of the 2010-11, 2011-12, 2012-13, and 2013-14 seasonal influenza vaccines in pregnancy: birth defects, spontaneous abortion, preterm delivery, and small for gestational age infants, a study from the cohort arm of VAMPSS. Vaccine. 2016;34:4443-9.

9. Sperling RS, Riley LE. Immunization and emerging infections expert work group. Influenza vaccination, pregnancy safety, and risk of early pregnancy loss. Obstet Gynecol. 2018:131:799-802.

10. Giles ML, Krishnaswamy S, Macartney K, Cheng A. The safety of inactivated influenza vaccines in pregnancy for birth outcomes: a systematic review. Hum Vaccines Immunother. 2019;15:687-99.

11. World Health Organization. Weekly epidemiological record Relevé épidémiologique hebdomadaire. 2012;:461-76.

12. Committee on Obstetric Practice and Immunization Expert Work Group, Centers for Disease Control and Prevention's Advisory Committee on Immunization, United States, American College of Obstetricians and Gynecologists. Committee opinion no. 608: influenza vaccination during pregnancy. Obstet Gynecol. 2014;124:648-51.

13. Blanchard-Rohner G, Meier S, Ryser J, Schaller D, Combescure C, Yudin MH et al. Acceptability of maternal immunization against influenza: the critical role of obstetricians. J Matern-Fetal Neonatal Med Off J Eur Assoc Perinat Med Fed Asia Ocean Perinat Soc Int Soc Perinat Obstet. 2012;25:1800-9.

14. Ko HS, Jo YS, Kim YH, Park Y-G, Moon HB, Lee Y, et al. Knowledge, attitudes, and acceptability about influenza vaccination in Korean women of childbearing age. Obstet Gynecol Sci. 2015;58:81-9.

15. Ahluwalia IB, Jamieson DJ, Rasmussen SA, D'Angelo D, Goodman D, Kim H. Correlates of seasonal influenza vaccine coverage among pregnant women in Georgia and Rhode Island. Obstet Gynecol. 2010;116:949-55.

16. Chamberlain AT, Seib K, Ault KA, Orenstein WA, Frew PM, Malik F, et al. Factors associated with intention to receive influenza and tetanus, diphtheria, and Acellular pertussis (Tdap) vaccines during pregnancy: a focus on vaccine hesitancy and perceptions of disease severity and vaccine safety. PLoS Curr. 2015;7.

17. Maher L, Hope K, Torvaldsen S, Lawrence G, Dawson A, Wiley K, et al. Influenza vaccination during pregnancy: coverage rates and influencing factors in two urban districts in Sydney. Vaccine. 2013;31:5557-64.

18. Blondel B, Coulm B, Bonnet C, Goffinet F, Le Ray C. National Coordination Group of the National Perinatal Surveys. Trends in perinatal health in metropolitan France from 1995 to 2016: results from the French National Perinatal Surveys. J Gynecol Obstet Hum Reprod. 2017:46:701-13.

19. Surveillance_of_influenza_and_other_respiratory_viruses_in_the_UK_2016_ to_2017.pdf. https://www.gov.uk/government/uploads/system/uploads/ attachment_data/file/613493/Surveillance_of_influenza_and_other_ respiratory_viruses_in_the_UK_2016_to_2017.pdf. Accessed 11 Jun 2017.

20. Ding $H$, Black $C L$, Ball S, Fink RV, Williams WW, Fiebelkorn AP, et al. Influenza vaccination coverage among pregnant women - United States, 2016-17 influenza season. MMWR Morb Mortal Wkly Rep. 2017;66:1016-22.

21. Immunization and Infectious Diseases | Healthy People 2020. https://www. healthypeople.gov/2020/topics-objectives/topic/immunization-andinfectious-diseases/objectives. .

22. calendrier_vaccinations_2018.pdf. http://solidarites-sante.gouv.fr/IMG/pdf/ calendrier_vaccinations_2018.pdf. Accessed 8 Mar 2018.

23. Yudin MH, Salaripour M, Sgro MD. Pregnant women's knowledge of influenza and the use and safety of the influenza vaccine during pregnancy. J Obstet Gynaecol Can JOGC J Obstet Gynecol Can JOGC. 2009:31:120-5.

24. Offeddu V, Tam CC, Yong TT, Tan LK, Thoon KC, Lee N, et al. Coverage and determinants of influenza vaccine among pregnant women: a crosssectional study. BMC Public Health. 2019;19:890.
25. Wilson RJ, Paterson P, Jarrett C, Larson HJ. Understanding factors influencing vaccination acceptance during pregnancy globally: a literature review. Vaccine. 2015;33:6420-9.

26. Yuen CYS, Tarrant M. Determinants of uptake of influenza vaccination among pregnant women - a systematic review. Vaccine. 2014;32:4602-13.

27. Loubet P, Guerrisi C, Turbelin C, Blondel B, Launay O, Bardou M, et al. Influenza during pregnancy: incidence, vaccination coverage and attitudes toward vaccination in the French web-based cohort G-GrippeNet. Vaccine. 2016;34:2390-6.

28. Blondel B, Pierrat V, Foix-L'Hélias L. Changes in conditions at birth in France from 1995 to 2016: results of the National Perinatal Surveys. Arch Pediatr Organe Off Soc Francaise Pediatr. 2018;25:245-6.

\section{Publisher's Note}

Springer Nature remains neutral with regard to jurisdictional claims in published maps and institutional affiliations.
Ready to submit your research? Choose BMC and benefit from:

- fast, convenient online submission

- thorough peer review by experienced researchers in your field

- rapid publication on acceptance

- support for research data, including large and complex data types

- gold Open Access which fosters wider collaboration and increased citations

- maximum visibility for your research: over $100 \mathrm{M}$ website views per year

At BMC, research is always in progress.

Learn more biomedcentral.com/submissions 